\title{
Cholesterol Cleft
}

National Cancer Institute

\section{Source}

National Cancer Institute. Cholesterol Cleft. NCI Thesaurus. Code C120870.

A finding of an empty space in a histological section of paraffin-embedded tissue created by the dissolution of cholesterol crystals. 